\title{
Colloidal rare earth phosphovanadates for luminescent thermometry
}

\section{Gustavo F. Derroso*, Rafael V. Perrella, Gabriela Guida, Paulo C. de Sousa Filho}

\section{Abstract}

The partial dissolution of orthophosphate ions into yttrium orthovanadate lattices led to an enhancement of the luminescence of orthovanadate groups. The combination of the luminescence of vanadate ions with emissions of lanthanide ions can be used to develop self-calibrating optical thermometers with two emitting centers in the same lattice. In this sense, europium(III)-doped yttrium orthovanadate particles containing different amounts of phosphate ions $(x=0,0.05,0.10,0.20,0.30,0.40$ and 1$)$ were prepared by hydrothermal synthesis. The XRD patterns confirmed the formation of solid solutions with tetragonal zircon-type structure. The luminescence analysis showed that composition with $20 \%$ of phosphate ions show comparably intense emissions from vanadate groups and europium(III) ions, which is potentially applicable inn ratiometric temperature measurements via two-center downshift luminescence. Additional studies using trivalent thulium and erbium as activators can extend de applicability of the material by enabling dual downshift/upconversion thermometry.

Key words: Rare earths, luminescence, thermometry.

\section{Introduction}

Rare earth (RE) phosphovanadates are potentially attractive systems for luminescence thermometry because $\mathrm{PO}_{4}{ }^{3-}$ groups can be dissolved in the $\mathrm{REVO}_{4}$ host lattice, leading to an enhancement of $\mathrm{VO}_{4}{ }^{3-}$ luminescence. ${ }^{1}$ Hence, the $\mathrm{VO}_{4}{ }^{3-}$ emissions can be compared ratiometrically with emissions from activator $\mathrm{Ln}^{3+}$ ions, thus providing self-calibrating optical thermal sensing. With this in mind, the main objective is to investigate the $\mathrm{Y}_{0.999} \mathrm{Eu}_{0.001} \mathrm{~V}_{1-\mathrm{x}} \mathrm{P}_{\mathrm{x}} \mathrm{O}_{4}$ system as a ratiometric thermal sensor. For this, we synthesized differents compositions of phosphovanadates to obtain systems with an enhancement of $\mathrm{VO}_{4}{ }^{3-}$ luminescence, thus enabling the ratiometric comparison with emissions of $\mathrm{Eu}^{3+}$. After compositional optimization, it is possible to advance to thermometry studies.

\section{Results and Discussion}

The different compositions of $\mathrm{Y}_{0.999} \mathrm{Eu}_{0.001} \mathrm{~V}_{1-\mathrm{x}} \mathrm{P}_{\mathrm{x}} \mathrm{O}_{4} \quad(\mathrm{x}=0$, $0.05,0.10,0.20,0.30,0.40$ and 1 ) were synthetized by a hydrothermal method ${ }^{2}$. The XRD patterns confirmed the formation of tetragonal zircon-type structure without secondary phases, and signals of solid solutions revealed peak broadening and displacement to larger angles (Image 1).

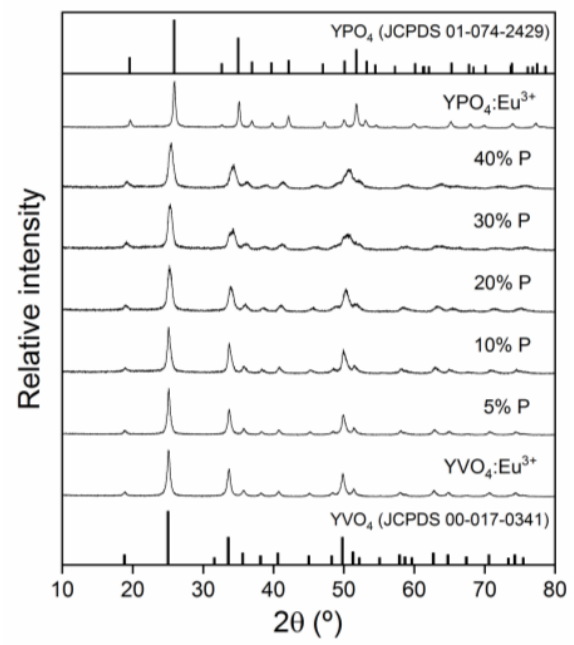

Image 1. X-ray diffractograms of different compositions of synthesized $\mathrm{Y}_{0.999} \mathrm{Eu}_{0.001} \mathrm{~V}_{1-\mathrm{x}} \mathrm{P}_{\mathrm{x}} \mathrm{O}_{4}$ by hydrothermal synthesis.
The solids presented intense photoluminescence when excited at the $\mathrm{VO}_{4}{ }^{3-}$ absorption at $270 \mathrm{~nm}$, giving rise to the characteristic $\mathrm{f}-\mathrm{f}$ transitions of $\mathrm{Eu}^{3+}$ (Image 2.). Moreover, the $\mathrm{x}=0.20$ composition displayed intensified $\mathrm{VO}_{4}{ }^{3-}$ emissions when compared to the ${ }^{5} D_{0} \rightarrow{ }^{7} F_{2}$ transition of $\mathrm{Eu}^{3+}$.

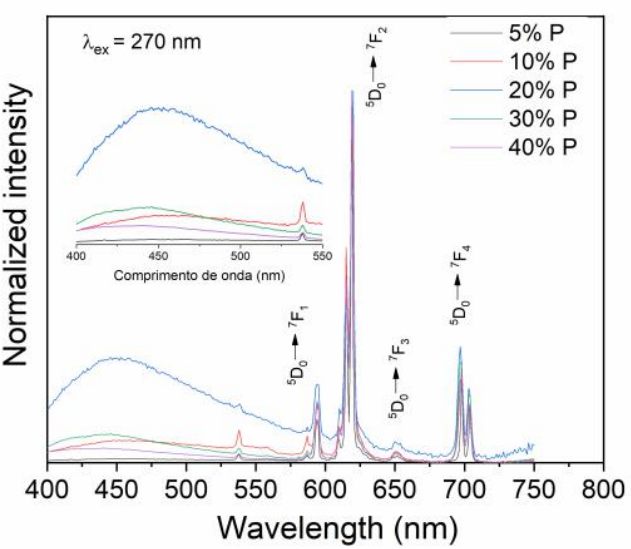

Image 2. Emission spectra $\left(\lambda_{\mathrm{exc}}=270 \mathrm{~nm}\right)$ of different compositions of synthesized $\mathrm{Y}_{0.999} \mathrm{Eu}_{0.001} \mathrm{~V}_{1-\mathrm{x}} \mathrm{P}_{\mathrm{x}} \mathrm{O}_{4}$ by hydrothermal synthesis.

\section{Conclusions}

The $\mathrm{Y}_{0.999} \mathrm{Eu}_{0.001} \mathrm{~V}_{1-\mathrm{x}} \mathrm{P}_{\mathrm{x}} \mathrm{O}_{4}$ particles enable ratiometric temperature measurements by monitoring two emitting centers in the same matrix via downshift luminescence. Additional studies comprising $\mathrm{Er}^{3+}$ and $\mathrm{Tm}^{3+}$ as activators can extend the applicability of the phosphovanadate systems by enabling dual downshift/upconversion thermometry.

\section{Acknowledgement}

The authors thank CNPq, FAEPEX, CAPES and FAPESP for financial support.

${ }^{1}$ de Sousa Filho, P. C. et al.; J. Phys. Chem. C 2015, 119, 24062

${ }^{2}$ Shen, D. et al.; CrystEngComm 2018, 20, 5180. 